\title{
Vaccinate before the next pandemic?
}

\author{
Klaus Stöhr of Novartis argues that pre-pandemic immunization with a cocktail of likely strains could be a \\ cheap, practical and equitable way to protect people against influenza.
}

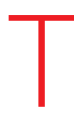
he past 12 months are testimony that alternative ways are needed to prepare for pandemics. When swine influenza spread around the world from Mexico during April and May last year, governments and vaccine producers faced the same dilemma: no one knew how much vaccine to order or produce. There was little option but to prepare for the worst, because it takes at least six months to produce significant quantities of vaccine. Several companies, including Novartis, stepped up preparations in May. By the time the World Health Organization (WHO) declared the outbreak a pandemic in June ${ }^{1}$, manufacturers were geared up to maximum capacity.

By December, with the outbreak already past its second peak, 495 million doses had been made - a record rate of production, yet only enough to cover $10 \%$ of the world's population. The WHO estimates that by June 2010 global supply will have reached around 1.3 billion doses, far too little too late if the worst forecasts had played out. Had that happened, governments would have been blamed for not securing more pandemic vaccine earlier. Yet many governments are now being criticized for squandering taxpayers' money on supplies that were not needed.

There is no sign that global equitable access to influenza vaccines could be established any time soon ${ }^{2}$. And if it was, how could it be successful if the limited supply was only reallocated and not increased?

A different approach is needed. An increasingly discussed method is to immunize people against pandemic-type viruses before a pandemic strikes. This could limit the spread of the virus in the early stages of a pandemic and significantly reduce the peak demand for vaccine. It would thus free up supply for countries where vaccination is patchy, or that do not have the infrastructure or budget to purchase any vaccine.

\section{Existing infrastructure}

Pre-pandemic immunization could be done cost-effectively via existing immunization infrastructure. For example, where there is universal seasonal immunization, such as in the United States and Ontario, pandemic-type vaccines could be added to and administered with seasonal vaccines; other regions could offer them as stand-alone formulations. A more radical suggestion is to add pandemic antigens to routine child-immunization programmes, a method likely to work best in developing countries that do not have regular adult-immunization programmes. People may need immunizing only once or twice to get at least some protection from a virus for years or even for life. Furthermore, vaccinating $20 \%$ of a population before a pandemic would prevent as many cases as vaccinating $60 \%$ after the first wave has struck, because it could mean that a certain number of people would never get infected and would not pass on the virus (see graphic).

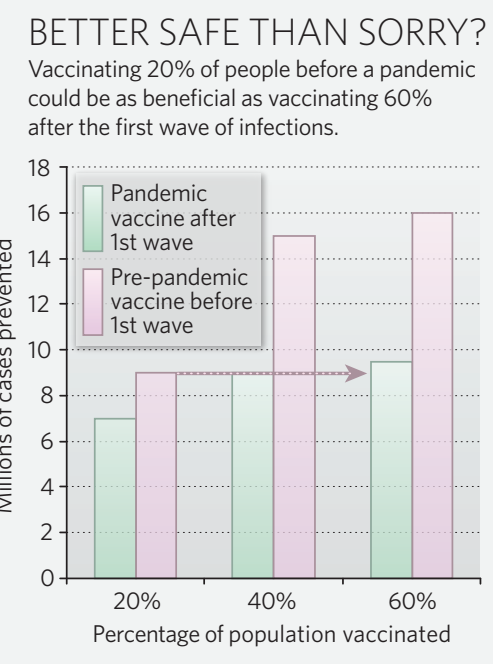

Pre-pandemic vaccination has been controversial for two major reasons. The first is efficacy, because there is no way of telling which influenza subtype will hit next. Pre-pandemic formulations would contain a cocktail of strains most likely to cause the next pandemic, generally agreed to be $\mathrm{H} 2, \mathrm{H} 5, \mathrm{H} 7$ and $\mathrm{H} 9$. They should also enhance the effectiveness of the antigens by including adjuvants designed to provoke a long-term immune response to a range of virus subtypes, even viruses genetically different from the original strain ${ }^{3}$. Studies are ongoing on two further important questions: how long people remain protected after being primed with a pre-pandemic vaccine; and whether giving several antigens together interferes with the length of the immune response.

The other main concern is safety. Adequate safety data are lacking on the large-scale, repetitive and long-term use of recently approved adjuvants, but the use of millions of doses of adjuvant-containing vaccine in the recent $\mathrm{H} 1 \mathrm{~N} 1$ pandemic has helped to plug that gap. In March, the European Medicines Agency reported that since October more than 42 million Europeans, nearly half a million of whom were pregnant, had been vaccinated with one of the three pandemic vaccines authorized for use in the European Union, with no more adverse reactions than would be expected from a seasonal influenza vaccine ${ }^{4}$. And by the end of last year, more than $10 \mathrm{H} 1$ vaccines were developed through clinical trials involving tens of thousands of subjects around the world, again with safety profiles comparable to seasonal flu vaccines.

\section{Political difficulties}

Despite the compelling case for pre-pandemic immunization, few public-health decisionmakers are taking it seriously. Spending money on a medical threat that hasn't yet materialized is politically difficult and requires strong justification. Integrating pre-pandemic immunization into existing immunization programmes around the world would also take several years.

Yet the stage is set for a global public-health leader to carry out an in-depth assessment into the practicalities and cost-effectiveness of this approach and its long-term effect on public health. I invite those who find it unsurprising that an employee of a leading vaccine-producer holds this view to come up with alternative solutions to the sobering reality of 'too-little-toolate' supply when vaccine production begins after a pandemic strain emerges. One thing is clear: something has to change, because the current approach would leave at least $80 \%$ of the world's population unprotected in the face of a new pandemic, most of them in developing countries - and that is unacceptable.

Klaus Stöhr is vice-president of influenza strategy at Novartis Vaccines and Diagnostics, Cambridge, Massachusetts 02139, USA, and former head of the WHO Global Influenza Programme in Geneva, Switzerland. e-mail: klaus.stohr@novartis.com

\footnotetext{
1. Chan, M. World Now at the Start of 2009 Influenza Pandemic (WHO, 2009); available at go.nature.com/5tufc3

2. Fidler, D. P. PLoS Med. 7, e1000247 (2010).

3. Stephenson, I. et al. N. Engl. J. Med. 359, 1631-1633 (2008).

4. European Medicines Agency Fourteenth Pandemic Pharmacovigilance Update (EMA, 2010); available at go.nature.com/GnDjSD
}

A conflict of interests statement accompanies this article online at go.nature.com/NrbL7N. 